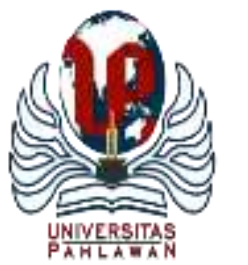

Edukatif : Jurnal Ilmu Pendidikan Volume 4 Nomor 1 Tahun 2022 Halm 498 - 507

EDUKATIF: JURNAL ILMU PENDIDIKAN

Research \& Learning in Education

https://edukatif.org/index.php/edukatif/index

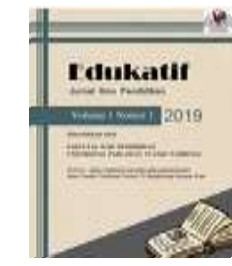

\title{
Pengembangan Media Pembelajaran Adobe Flash CS6 pada Mata Pelajaran Teknologi Informasi dan Komunikasi untuk meningkatkan Hasil Belajar Siswa SMP
}

\author{
Zamza Satria Edwar $^{1 凶}$, Romli Ardie ${ }^{2}$, Lukman Nulhakim ${ }^{3}$ \\ Teknologi Pendidikan, Universitas Sultan Ageng Tirtayasa, Indonesia ${ }^{1,2,3}$ \\ E-mail : $\underline{7772190056 @ \text { untirta.ac.id }}$, $\underline{\text { romli.ardie@ untirta.ac.id }}^{2}, \underline{\text { lukman.nulhakim@ @untira.ac.id }}^{3}$
}

\begin{abstract}
Abstrak
Penelitian ini bertujuan untuk menghasilkan media pembelajaran Adobe Flash CS6 yang efektif dan layak digunakan dalam pembelajaran TIK dan juga dapat meningkatkan hasil belajar siswa. Penelitian ini menggunakan metode penelitian Research and Development $(\mathrm{RnD})$. Prosedur penelitian yang digunakan dalam pengembangan ini menggunakan langkah atau tahapan 4D. Subjek pada penelitian ini adalah siswa/i kelas IX SMP Negeri 24 Kota Serang. Teknik pengumpulan data dilakukan dengan observasi dan angket. Hasil dari penelitian ini menunjukkan bahwa media pembelajaran Adobe Flash CS6 yang dikembangkan sudah efektif dan layak digunakan. Dalam menggunakan media pembelajaran ini terbukti bahwa media sudah sangat sesuai digunakan dalam meningkatkan hasil belajar siswa pada pembelajaran TIK di SMP Negeri 24 Kota Serang.
\end{abstract}

Kata Kunci: media pembelajaran, Adobe Flash CS6, TIK

\begin{abstract}
This study aims to produce Adobe Flash CS6 learning media that is effective and suitable for use in ICT learning and can also improve student learning outcomes. This study uses the Research and Development $(R n D)$ research method. The research procedure used in this development uses $4 D$ steps or stages. The subjects in this study were students of class IX SMP Negeri 24 Serang City. Data collection techniques were carried out by observation and questionnaires. The results of this study indicate that the developed Adobe Flash CS6 learning media is effective and feasible to use. In using this learning media, it is proven that the media is very suitable to be used in improving student learning outcomes in ICT learning at SMP Negeri 24 Serang City.
\end{abstract}

Keywords: instructional Media, Adobe Flash CS6,ICT

Copyright (c) 2022 Zamza Satria Edwar, Romli Ardie, Lukman Nulhakim

$\triangle$ Corresponding author

Email : 7772190056@untirta.ac.id

DOI : https://doi.org/10.31004/edukatif.v4i1.1576

ISSN 2656-8063 (Media Cetak)

ISSN 2656-8071 (Media Online) 
DOI: https://doi.org/10.31004/edukatif.v4i1.1576

\section{PENDAHULUAN}

Pendidikan adalah upaya sadar dan terencana untuk menciptakan suasana belajar dan proses belajar bagi peserta didik agar dapat secara aktif mengembangkan potensi, pengendalian diri, kepribadian, kecerdasan, karakter, dan keterampilannya (Depdikbud, 2014). Pemerintah Republik Indonesia telah bertekad untuk memberikan kesempatan kepada seluruh warga Negara Indonesia untuk menikmati pendidikan yang bermutu, sebagai langkah utama meningkatkan taraf hidup warga negara. Sebagai agen pembaru, pendidikan bertanggung jawab mengembangkan dan mewariskan nilai untuk dinikmati anak didik, selanjutnya nilai dimaksud akan ditransfer ke dalam kehidupan sehari-hari.

Upaya yang dilakukan dalam rangka memenuhi tuntutan tersebut adalah dengan jalan memanfaatkan teknologi pendidikan, khususnya proses pembelajaran melalui pendekatan teknologis. Teknologi pendidikan mempunyai karakteristik tertentu yang sangat relevan bagi kepentingan pendidikan. Teknologi pendidikan memungkinkan adanya (1) Penyebaran informasi secara luas, merata, cepat, seragam dan terintegrasi, sehingga dengan demikian pesan dapat disampaikan sesuai dengan isi yang dimaksud, (2) Teknologi pendidikan dapat menyajikan materi secara logis, ilmiah dan sistematis serta melengkapi, menunjang, memperjelas konsep-konsep, prinsip-prinsip atau proposisi materi pelajaran, (3) Teknologi pendidikan menjadi partner guru dalam rangka mewujudkan proses belajar mengajar yang efektif, efisien dan produktif sesuai dengan kebutuhan dan tuntutan anak didik, (4) Teknologi pendidikan dapat dimanfaatkan sebagai sumber belajar, dapat menyajikan materi secara lebih menarik, lebih-lebih jka disertai dengan kemampuan memanfaatkanya (Danim, 2010:3).

Dalam dunia pendidikan, komputer sudah menjadi sebuah media pembelajaran yang dapat membantu proses pembelajaran yang ada di Sekolah Menengah Pertama seperti media pembelajaran berbasis multimedia. Media pembelajaran merupakan faktor yang sangat penting dalam proses pembelajaran, guru juga harus menggunakan media sebagai bahan ajar untuk meyampaikan materi kepada siswa, karenga dengan menggunakan media akan dipahami oleh siswa dengan baik, salah satu media yang baik untuk digunakan adalah media video animasi (Wahyuningtyas \& Sulasmono, 2020). Video animasi adalah suatu media audio visual yang dirangkai melalui proses penciptaan efek gerak atau perubahan bentuk sehingga menampilkan gambar berurutan membuat penonton merasakan adanya ilustrasi pada gambar yang ditampilkan. Media pembelajaran video animasi dapat menyajikan objek secara rinci serta dapat menunjang dalam menguasi pembelajaran, dan dapat dimanfaatkan untuk penyampaian materi kepada anak dengan cara yang menyenangkan sehingga anaktidak mudah bosan dan jenuh (Ani Wahyuni, Rame Santoso, \& Sidik, 2019; Apriansyah, 2020; JANNAH \& JULIANTO, 2018). Multimedia adalah pemanfaatan komputer untuk menggabungkan teks, grafik, audio, dan gambar bergerak (video dan animasi) menjadi satu kesatuan dengan link dan tool yang tepat sehingga memungkinkan pemakai multimedia dapat melakukan navigasi, interaksi, berkreasi dan berkomuniasi (Suyanto, 2003:20-21). Sementara Hofstetter yang dikutip Suyanto (2005: 21) multimedia adalah pemanfaatan komputer untuk membuat dan menggunakan teks, grafik, audio, gambar bergerak (video dan animasi) dengan menggabungkan link dan tool yang memungkinkan pemakai melakukan navigasi, berinteraksi, dan berkomunikasi.

Media pembelajaran interaktif adalah suatu sistem penyampaian pengajaran yang menyajikan materi video rekaman dengan pengendalian komputer kepada penonton (siswa) yang tidak hanya mendengar, melihat video, dan suara, tetapi siswa juga dapat memberikan respon yang aktif dan respon itu yang menentukan kecepatan dan sekuensi penyajian (Arsyad, 2002:36). Rob Philips dalam Nugroho (2008) menjelaskan makna interaktif sebagai suatu proses pemberdayaan siswa untuk mengendalikan lingkungan belajar. Dalam konteks ini lingkungan belajar yang dimaksud adalah belajar dengan menggunakan komputer serta media pembelajaran dibuat dengan bantuan perangkat lunak (Software). Multimedia memiliki keunggulan 
500 Pengembangan Media Pembelajaran Adobe Flash CS6 pada Mata Pelajaran Teknologi Informasi dan Komunikasi untuk meningkatkan Hasil Belajar Siswa SMP - Zamza Satria Edwar, Romli Ardie, Lukman Nulhakim

DOI: https://doi.org/10.31004/edukatif.v4i1.1576

diantaranya membuat pembelajaran lebih bermakna, meningkatkan pengalaman belajar dan peserta didik menjadi lebih nyaman sehingga membuat peserta didik termotivasi, memiliki minat dan bersemangat (Daesang, Doong-Joong, Woo-Hyung, 2013, p.80). Salah satu perangkat lunak yang dapat digunakan untuk mengembangkan media pembelajaran adalah Adobe Flash CS6 atau lebih dikenal dengan sebutan Flash CS6 adalah salah satu program unggulan dari Adobe Sistem yang khusus digunakan untuk membuat animasi gambar vektor.

Dalam penggunaan Adobe Flash CS6 ini diharapkan mampu membuat media pembelajaran dan materi yang disampaikan dapat direspon positif oleh siswa. Penggunaan Adobe Flash CS6 sebagai media pembelajaran di SMP Negeri 24 Kota Serang khususnya mata pelajaran TIK belum digunakan, media pembelajaran yang digunakan di SMP Negeri 24 Kota Serang masih kurang bisa menarik minat belajar siswa karena masih terbatas pada penggunaan LKPD dan buku paket. Dengan menggunakan Adobe Flash CS6 ini diharapkan mampu membuat media pembelajaran dan materi yang disampaikan dapat direspon positif oleh siswa. Penggunaan Adobe Flash CS6 sebagai media pembelajaran di SMP Negeri 24 Kota Serang khususnya mata pelajaran TIK belum digunakan, media pembelajaran yang digunakan di SMP Negeri 24 Kota Serang masih kurang bisa menarik minat belajar siswa karena masih terbatas pada penggunaan LKPD dan buku paket.

Setiap siswa yang melakukan aktivitas termasuk kegiatan belajar selalu mengharapkan hasil yang baik. Hasil belajar adalah kemampuan-kemampuan yang dimiliki siswa setelah ia menerima pengalaman belajarnya (Sudjana, 2004). Menurut pendapat lain hasil belajar adalah suatu proses aktivitas mental seseorang dalam berinteraksi dengan lingkungannya sehingga menghasilkan perubahan tingkah laku yang bersifat positif baik perubahan dalam aspek pengetahuan, sikap, maupun psikomotor (Sanjaya, 2010:229). Hasil belajar siswa yang diharapkan adalah kemampuan lulusan yang utuh yang mencakup kemampuan kognitif, kemampuan psikomotor dan kemampuan afektif atau perilaku (Depdiknas, 2003). Kemampuan kognitif adalah kemampuan berpikir secara hirarki yang terdiri dari pengetahuan, pemahaman, aplikasi, analisis, sintesis dan evaluasi. Kemampuan psikomotor berkaitan dengan kemampuan gerak dan banyak terdapat dalam pelajaran praktik. Sedangkan kemampuan afektif siswa meliputi perilaku sosial, sikap, minat disiplin dan sejenisnya.

Sejalan dengan hal tersebut pada hasil penelitian (Fuady, 2015), menyatakan bahwa pengembangan media animasi Flash Player dapat dikategorikan layak untuk digunakan dalam materi laju reaksi, dimana dari hasil angket validasi yang diberikan kepada tiga validator terhadap produk yang dikembangkan memperoleh rata-rata nilai $75 \%$ dan berdasarkan hasil observasi aktivitas siswa selama proses pembelajaran menggunakan produk media animasi Flash Player dengan hasil nilai rata-rata yang diperoleh sebesar $85 \%$ menunjukkan aktivitas siswa dapat dikategorikan dengan sangat baik. Menurut penelitian (Saselah et al., 2017) menunjukkan bahwa media pembelajaran multimedia interaktif berbasis Adobe Flash CS6 yang dihasilkan layak digunakan dalam pembelajaran kesetimbangan kimia di SMK dan mendapat respon yang positif dari siswa. Penelitian lain yang dilakukan (Sukarmin,2019) bahwa multimedia interaktif dan kit dikategorikan sangat layak dengan persentase kelayakan $\geq 61 \%$. Hasil belajar siswa meningkat setelah uji coba. Hasil respon siswa menunjukkan bahwa multimedia interaktif dan kit respon positif karena lebih dari $61 \%$ memberikan respon positif. Persamaan penelitian terdahulu dan penelitian ini adalah software yang digunakan sama-sama menggunakan Adobe Flash. Perbedaan terletak pada materi yang disajikan dan tempat penelitian.

Maka dari itu media pembelajaran yang akan penulis buat adalah berupa media yang berbentuk tutorial sehingga siswa mampu belajar sesuai dengan step by stepnya dan terdapat $\mathrm{KI} / \mathrm{KD}$, materi, latihan dan kuis. Berdasarkan latar belakang masalah di atas, perlu dilakukan penelitian tentang "Pengembangan Media Pembelajaran Adobe Flash CS6 Pada Mata Pelajaran TIK di SMP Negeri 24 Kota Serang”. 
501 Pengembangan Media Pembelajaran Adobe Flash CS6 pada Mata Pelajaran Teknologi Informasi dan Komunikasi untuk meningkatkan Hasil Belajar Siswa SMP - Zamza Satria Edwar, Romli Ardie, Lukman Nulhakim

DOI: https://doi.org/10.31004/edukatif.v4i1.1576

\section{METODE PENELITIAN}

Subjek dari penelitian ini siswa/i kelas IX SMP Negeri 24 Kota Serang. Penelitian ini merupakan penelitian dan pengembangan (Research and Development) yaitu metode penelitian yang digunakan untuk menghasilkan produk tertentu dan menguji keefektifan produk tersebut (Sugiyono, 2009:407). Adapun tahap pengembangan yang digunakan adalah 4D (Four-D). Teknik pengumulan data pada penelitian ini adalah menggunakan angket dan tes. Instrumen berupa angket yang dimaksud untuk mengevaluasi kualitas pengembangan media dan Instrumen berupa tes untuk mengetahui hasil belajar peserta didik. Teknik analisis data pada penelitian ini mencakup seluruh kegiatan menganalisa, memakai dan menarik kesimpulan dari semua data yang terkumpul dalam pelaksanaan penelitian ini.

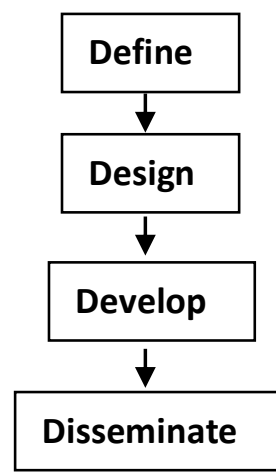

\section{Gambar 1. Tahap penelitian 4D}

\section{HASIL DAN PEMBAHASAN PENELITIAN}

Pengembangan media pembelajaran Adobe Flash CS6 pada mata pelajaran TIK di SMP Negeri 24 Kota Serang melalui beberapa tahapan yaitu :

\section{Define}

Pada tahap ini, peneliti melakukan observasi untuk mengidentifikasi masalah yang dihadapi pengguna yaitu guru dan siswa di SMP Negeri 24 Kota Serang dalam pelaksanaan pembelajaran. Proses pembelajaran di SMP Negeri 24 Kota Serang dari hasil observasi penulis guru kurang memanfaatkan teknologi dimana belum adanya rancangan suatu sistem pembelajaran yang menggunakan media pembelajaran interaktif. Pada saat penyampaian materi pembelajaran guru masih menggunakan metode ceramah, dimana guru lebih aktif dari pada siswa. Hal itulah yang membuat siswa merasa dirugikan karena siswa tidak bisa mengakses kembali materi yang disampaikan oleh guru, sehingga pembelajaran menjadi tidak efektif dan efisien pada saat pertemuan di sekolah, oleh sebab itu perlu adanya metode baru yang harus digunakan guru untuk menyampaikan materi baru seperti menggunakan media pembelajaran yang akan penulis rancang menggunakan software Adobe Flash CS6. Hal ini bertujuan agar proses pembelajaran bisa berjalan dengan lancar dan peserta didik bisa aktif dan fokus terhadap pembelajaran yang diberikan oleh guru.

Dalam tahap ini, terdapat beberapa analisis sebelum menghasilkan sebuah media. Beberapa analisis tersebut yaitu:

\section{a. Analisis ujung depan}

Analisis ujung depan merupakan proses identifikasi masalah-masalah yang dihadapi saat melaksanakan peroses pembelajaran. Analisis ini dilakukan dengan tujuan untuk melakukan pengamatan secara langsung. Hasil dari pengamatan menunjukkan bahwa masih terdapat beberapa permasalahan yang dihadapi dalam proses pembelajaran. Permasalahan tersebut adalah belum terdapat media pembelajaran yang digunakan sebagai bahan pembelajaran yang dapat menarik minat belajar siswa, 
502 Pengembangan Media Pembelajaran Adobe Flash CS6 pada Mata Pelajaran Teknologi Informasi dan Komunikasi untuk meningkatkan Hasil Belajar Siswa SMP - Zamza Satria Edwar, Romli Ardie, Lukman Nulhakim

DOI: https://doi.org/10.31004/edukatif.v4i1.1576

proses pembelajaran yang masih terpaku pada guru, kurangnya pemahaman siswa terhadap setiap langkah kerja yang dilakukan dalam pembelajaran, siswa tidak dapat belajar secara mandiri karena tidak adanya bahan ajar yang memadai. Pada tahap ini juga dilakukan analisis terhadap silabus mata pelajaran TIK agar dapat menentukan materi-materi yang akan dimuat dalam media yang akan dirancang.

\section{b. Analisis siswa}

Pada dasarnya sistem pembelajaran yang diterapkan pada mata pelajaran TIK masih terpaku pada penjelasan guru. Hingga saat ini masih belum terdapat media pembelajaran berupa media pembelajaran interaktif yang digunakan. Hal seperti ini membuat siswa menjadi tidak dapat belajar secara mandiri melainkan hanya dapat belajar ketika peroses pembelajaran berlangsung. Selain itu, langkah kerja yang dilakukan pada saat melakukan pembelajaran juga kurang dipahami secara detail dan terperinci karena hanya mengandalkan instruksi yang diberikan guru pada saat pembelajaran berlangsung.

\section{c. Analisis tugas}

Perumusan tugas dilakukan dengan cara memetakan materi pembelajaran berdasarkan dari analisis siswa. Hasil analisis ini menjadi beberapa materi pokok, sehingga materi yang ditampilkan pada media pembelajaran disusun menjadi beberapa bagian. Pada tiap materi pokok diberikan beberapa tugas agar dapat menguasai media pembelajaran secara mendalam. Tugas yang diberikan berupa pencarian literatur yang harus diselesaikan pada tiap materi pokok.

\section{d. Analisis Konsep}

Perumusan konsep dilakukan dengan cara mengidentifikasi materi yang disajikan pada media pembelajaran yang dikembangkan, dengan mengacu pada silabus mata pelajaran TIK yang diterapkan SMP Negeri 24 Kota Serang. Silabus yang ada terdiri dari 8 kompetensi inti, tetapi yang dikembangkan pada media pembelajaran hanya 1 kompetensi inti yaitu mengenal microsoft excel. Selain itu, pembuatan media pembelajaran ini menggunakan software Adobe Flash CS6 sebagai Software utama, dan didukung oleh Software-software lain seperti Adobe Photoshop,CorelDraw, SWiSH max4.

\section{e. Perumusan Tujuan Pembelajaran}

Perumusan tujuan pembelajaran atau indikator pencapaian hasil belajar dibuat berdasarkan kompetensi dasar yang tercantum pada silabus. Kompetensi dasar dapat diuraikan menjadi beberapa materi. Materi yang disajikan pada media harus disesuaikan dengan tujuan pembelajaran.

Tabel 1 Tujuan Pembelajaran

\begin{tabular}{cl}
\hline No & \multicolumn{1}{c}{ Tujuan Pembelajaran } \\
\hline $\mathbf{1}$ & Memahami jenis representasi/ekstensi file \\
\hline $\mathbf{2}$ & $\begin{array}{l}\text { Menggunakan fitur-fitur lanjutan aplikasi Microsoft } \\
\text { Office, khususnya Microsoft Excel }\end{array}$ \\
\hline $\mathbf{3}$ & $\begin{array}{l}\text { Mengolah data dan melakukan komputasi sederhana } \\
\text { menggunakan Microsoft Excel }\end{array}$ \\
\hline $\mathbf{4}$ & $\begin{array}{l}\text { Merancang dan menggunakan algoritma sederhana } \\
\text { untuk mengumpulkan dan mengolah data }\end{array}$ \\
\hline Sumber : Terampil Menggunakan Informatika (Kurikulum 2013 edisi revisi terbaru)
\end{tabular}

\section{Design}

Pada tahap ini, peneliti melakukan perancangan awal dalam pembuatan media pembelajaran:

\section{a. Pemilihan Format}

Pemilihan format yang digunakan dalam media pembelajaran ini adalah sebagai berikut:

1. Jenis huruf yang digunakan disusun secara proporsional antara judul, susb bab, dan isi materi pembelajaran. 
503 Pengembangan Media Pembelajaran Adobe Flash CS6 pada Mata Pelajaran Teknologi Informasi dan Komunikasi untuk meningkatkan Hasil Belajar Siswa SMP - Zamza Satria Edwar, Romli Ardie, Lukman Nulhakim

DOI: https://doi.org/10.31004/edukatif.v4i1.1576

2. Penyajian tanda (icon) dibuat untuk memudahkan mengetahui halaman yang dianggap penting atau khusus serta dapat memperjelas isi materi.

3. Penyusunan materi diorganisasikan secara sistematis dan berurutan.

4. Daya tarik dibagian animasi dibuat dengan kombinasi warna, gambar, bentuk, dan ukuran huruf yang menarik.

\section{b. Perancangan Awal}

Perancangan awal merupakan bagaimana seorang guru merancang sebuah proses pembelajaran yang efektif dan efisien serta dapat mencapai tujuan pembelajaran. Guru TIK di SMP Negeri 24 Kota Serang menggunakan pendekatan saintifik dimana proses pembelajarannya dirancang sedemikian rupa agar peserta didik lebih aktif. Guru Guru TIK di SMP Negeri 24 Kota Serang sebelumnya hanya menggunakan metode ceramah dimana metode ceramah adalah cara penyampaian materi pembelajaran dengan melalui lisan/penjelasan langsung kepada siswa, jadi dengan adanya perancangan media pembelajaran Adobe Falsh CS6 ini guru dapat menggunakan media agar pembelajaran lebih menarik.

\section{Design}

Pada tahap ini, peneliti melakukan pembuatan produk media pembelajaran menggunakan Adobe Flash CS6, langkah-langkah yang dilakukan membuat story board, dengan tujuan mempermudah dalam pembuatan media dan untuk menentukan tahap pengembangan selanjutnya, agar bagian-bagian dari media pembelajran dapat tersusun dengan baik.

a) Penilaian ahli

Tahap penilaian media dilakukan agar media pembelajaran Adobe Flash CS6 yang dikembangkan dapat diketahui kelayakannya berdasarkan ahli media dan ahli materi.

1) Hasil Validasi Ahli Media

Ahli media dalam penelitian ini adalah Bapak Dr. Hidayatullah, M.Pd Selaku Dekan Fakultas Sains UIN Banten. Setelah beliau melihat dan mencoba produk Adobe Flash CS6 yang peneliti kembangkan maka diperoleh hasil rata-rata validasi oleh ahli media sebesar 72 dan skor maksimal 90 dengan persetase 80,2\% termasuk kriteria Baik. Berikut adalah hasil penilaian angket validasi oleh ahli media.

Tabel 2 Hasil Validasi Ahli Media

\begin{tabular}{clcccc}
\hline No & \multicolumn{1}{c}{ Aspek } & Skor & Skor Max & \% Skor & Kriteria \\
\hline 1 & Tampilan layar & 17 & 20 & $85 \%$ & SB \\
\hline 2 & Desain media & 8 & 10 & $80 \%$ & B \\
\hline 3 & Kualitas teknis & 19 & 25 & $76 \%$ & B \\
\hline 4 & Tampilan menu & 12 & 15 & $80 \%$ & B \\
\hline 5 & Pengoperasian media & 16 & 20 & $80 \%$ & B \\
\hline \multicolumn{2}{c}{ Rata-rata } & & & $80,2 \%$ & B \\
\hline
\end{tabular}

\section{2) Hasil Validasi Ahli Materi}

Ahli materi dalam penelitian ini adalah Bapak Mochammad Hikmattullah, S.Kom, Selaku Guru TIK SMP Negeri 24 Kota Serang. Setelah beliau melihat dan mencoba produk Adobe Flash CS6 yang peneliti kembangkan, kemudian memberikan penilaian terhadap angket validasi yang telah peneliti siapkan maka diperoleh hasil rata-rata validasi oleh ahli materi sebesar 109 dan skor maksimal 135 dengan persetase $83,1 \%$ termasuk kriteria Baik. Berikut adalah hasil penilaian angket validasi oleh ahli materi 
504 Pengembangan Media Pembelajaran Adobe Flash CS6 pada Mata Pelajaran Teknologi Informasi dan Komunikasi untuk meningkatkan Hasil Belajar Siswa SMP - Zamza Satria Edwar, Romli Ardie, Lukman Nulhakim

DOI: https://doi.org/10.31004/edukatif.v4i1.1576

Tabel 3 Hasil Validasi Ahli Materi

\begin{tabular}{clcccc}
\hline No & \multicolumn{1}{c}{ Aspek } & Skor & Skor Max & \% Skor & Kriteria \\
\hline 1 & $\begin{array}{l}\text { Kesesuaian materi dengan } \\
\text { KI/KD }\end{array}$ & 20 & 25 & $80 \%$ & B \\
\hline 2 & Keakuratan materi & 13 & 15 & $86,6 \%$ & SB \\
\hline 3 & $\begin{array}{l}\text { Pendukung materi } \\
\text { pembelajran }\end{array}$ & 13 & 15 & $86,6 \%$ & SB \\
\hline 4 & Kemutakhiran materi & 9 & 10 & $90 \%$ & SB \\
\hline 5 & Teknik penyajian & 34 & 45 & $75,6 \%$ & B \\
\hline 6 & $\begin{array}{l}\text { Ketepatan bahasa yang } \\
\text { digunakan }\end{array}$ & 20 & 25 & $80 \%$ & B \\
\hline & Rata-rata \\
\hline
\end{tabular}

3) Hasil Revisi Produk

Produk media yang sudah divalidasi selanjutnya direvisi sesuai dengan saran dan masukan ahli saat proses validasi hasil revisi yang didapatkan antara lain:

a. Saran ahli media

- Backsound dicari yang lebih nyaman untuk belajar

- Sistematika/urutan tampilan isi media

b. Saran ahli materi

- Meberikan animasi setiap menampilkan materi

b) Uji coba Perangkat Pembelajaran

Uji coba kelompok kecil dilakuan untuk mengetahui kelayakan produk tersebut sebelum digunakan dilapangan. Peneliti mengujikan media ini kepada 6 orang siswa kelas IX di SMP Negeri 24 Kota Serang, agar media pembelajaran Adobe Flash CS6 yang dikembangkan dapat mengetahui respon dari peserta didik.

Tabel 4 Tanggapan/Respon Peserta Didik Terhadap Media Pada Uji Coba Kelompok Kecil

\begin{tabular}{|c|c|c|c|c|c|c|c|c|c|c|c|}
\hline \multirow{2}{*}{$\begin{array}{c}\text { No. } \\
\text { Responden }\end{array}$} & \multicolumn{10}{|c|}{ No. Butir pertanyaan } & \multirow{2}{*}{$\begin{array}{c}\text { Jumlah Skor } \\
\%\end{array}$} \\
\hline & 1 & 2 & 3 & 4 & 5 & 6 & 7 & 8 & 9 & 10 & \\
\hline R.1 & 4 & 3 & 4 & 5 & 4 & 4 & 4 & 3 & 4 & 5 & $80 \%$ \\
\hline R.2 & 4 & 3 & 4 & 5 & 4 & 4 & 4 & 3 & 4 & 5 & $80 \%$ \\
\hline R.3 & 3 & 4 & 5 & 5 & 4 & 3 & 4 & 4 & 4 & 4 & $80 \%$ \\
\hline R.4 & 4 & 5 & 4 & 4 & 5 & 4 & 3 & 3 & 4 & 5 & $82 \%$ \\
\hline R.5 & 4 & 5 & 4 & 4 & 5 & 4 & 4 & 4 & 3 & 4 & $82 \%$ \\
\hline R.6 & 4 & 5 & 4 & 4 & 5 & 4 & 3 & 3 & 3 & 4 & $78 \%$ \\
\hline \multicolumn{11}{|c|}{ Rata-rata } & $80,3 \%$ \\
\hline
\end{tabular}

Pada uji coba kelompok kecil berdasarkan rata-rata jumlah skor keseluruhan sebesar 40,1 jika dipresentasekan menjadi 80,3\% dengan artian bahwa media pembelajaran dapat dikatakan "Baik".

\section{Disseminate}

Pada tahap ini, peneliti melakukan pengujian setelah digunakan dilapngan/ruang kelas kepada 33 orang siswa kelas IX di SMP Negeri 24 Kota Serang, agar media pembelajaran Adobe Flash CS6 yang dikembangkan dapat mengetahui hasil belajar dari peserta didik berikut hasil dari pengujian yang didapatkan dengan menggunakan bantuan software IBM SPSS statistics 25: 

Komunikasi untuk meningkatkan Hasil Belajar Siswa SMP - Zamza Satria Edwar, Romli Ardie, Lukman Nulhakim

DOI: https://doi.org/10.31004/edukatif.v4i1.1576

Tabel 5 Paired Samples Statistics Hasil Belajar TIK Paired Samples Statistics

\begin{tabular}{|c|c|c|c|c|c|}
\hline & & Mean & $\mathrm{N}$ & Std. Deviation & $\begin{array}{l}\text { Std. Error } \\
\text { Mean }\end{array}$ \\
\hline \multirow[t]{2}{*}{ Pair 1} & PRETEST & 51.82 & 33 & 13.039 & 2.270 \\
\hline & POSTTEST & 81.82 & 33 & 4.647 & .809 \\
\hline
\end{tabular}

Tabel 6 Paired Samples Test Hasil Belajar TIK

\begin{tabular}{|c|c|c|c|c|c|c|c|c|c|}
\hline & \multicolumn{9}{|c|}{ Paired Samples Test } \\
\hline & & \multicolumn{5}{|c|}{ Paired Differences } & \multirow[b]{3}{*}{$\mathrm{t}$} & \multirow[b]{3}{*}{ Df } & \multirow{3}{*}{$\begin{array}{l}\text { Sig. (2- } \\
\text { tailed) }\end{array}$} \\
\hline & & \multirow[b]{2}{*}{ Mean } & \multirow[b]{2}{*}{ Std. Deviation } & \multirow{2}{*}{$\begin{array}{c}\text { Std. Error } \\
\text { Mean }\end{array}$} & \multicolumn{2}{|c|}{$\begin{array}{l}\text { 95\% Confidence } \\
\text { Interval of the } \\
\text { Difference }\end{array}$} & & & \\
\hline & & & & & Lower & Upper & & & \\
\hline Pair 1 & $\begin{array}{l}\text { PRETEST - } \\
\text { POSTTEST }\end{array}$ & -30.000 & 11.110 & 1.934 & -33.940 & -26.060 & -15.512 & 32 & .000 \\
\hline
\end{tabular}

Keterangan: a.Jika nilai sig (2-tailed) $>0,05$ maka $\mathrm{H}_{0}$ diterima

b.Jika nilai sig (2-tailed) $\leq 0,05$ maka $\mathrm{H}_{0}$ ditolak

Pengujian hipotesis dapat dilihat dalam tabel paired sample T-test diatas dengan bunyi hipotesisnya sebagai berikut :

$\mathrm{H}_{\mathrm{o}}=$ tidak terdapat perbedaan sebelum dan sesudah hasil belajar TIK menggunakan media pembelajaran adobe flash cs6.

$\mathrm{H}_{1}=$ terdapat perbedaan sebelum dan sesudah hasil belajar TIK menggunakan media pembelajaran adobe flash cs6.

Penerimaan hipotesis membandingkan nilai sig (2-tailed) dengan $\alpha(0,05)$ dengan kriteria sebagai berikut :

1. Apabila nilai sig (2-tailed) $<0,05$ maka Ho ditolak.

2. Sebaliknya apabila sig (2-tailed) $\geq 0,05$ maka Ho diterima.

Berdasarkan tabel 6, diketahui bahwa hasil belajar TIK menggunakan media pembelajaran Adobe Flash CS6, memiliki nilai sig (2-tailed) $(0,000)$, maka dapat disimpulkan bahwa nilai sig (2-tailed) $(0,000) \leq(0,05)$ sehingga Ho ditolak, yang berarti terdapat perbedaan sebelum dan sesudah hasil belajar TIK menggunakan media pembelajaran Adobe Flash CS6. Hasil penelitian ini sesuai dengan hasil penelitian SERIN $(2011,183)$ juga menunjukkan ada peningkatan signifikan pada prestasi dan pemecahan masalah pada kelompok perlakuan yang menggunakan komputer berbasis ilmu pengetahuan dan teknologi. Hasil penelitian Wahyuni \& Djukri $(2016,90)$ menyimpulkan bahwa pembelajaran menggunakan media berbantuan komputer materi bryophyte efektif meningkatkan penguasaan konsep.

\section{KESIMPULAN}

Pengembangan media pembelajaran Adobe Flash CS6 pada mata pelajaran TIK yang dikembangkan sudah efektif dan layak digunakan berdasarkan hasil uji validitas dari ahli materi dan ahli media serta uji coba yang dilakukan. Pengembangan media pembelajaran ini juga sudah terbukti dapat meningkatkan hasil belajar siswa sebelum dan sesudah menggunakan media pembelajaran Adobe Flash CS6 ini. Berdasarkan hasil penelitian yang dilakukan pada pengembangan media pembelajaran ini diharapkan dapat digunakan sebagai media pembelajaran pada saat proses pembelajaran berlangsung agar pembelajaran yang dilakukan lebih 
506 Pengembangan Media Pembelajaran Adobe Flash CS6 pada Mata Pelajaran Teknologi Informasi dan Komunikasi untuk meningkatkan Hasil Belajar Siswa SMP - Zamza Satria Edwar, Romli Ardie, Lukman Nulhakim

DOI: https://doi.org/10.31004/edukatif.v4i1.1576

efektif dan efisien. Media pembelajaran Adobe Flash CS6 ini hanya terbatas pada mata pelajaran TIK saja, hendaknya untuk penelitian selanjutnya bisa dikembangkan media pembelajaran Adobe Flash CS6 ini pada mata pelajaran lainnya yang sesuai dengan kebutuhan siswa/peserta didik.

\section{DAFTAR PUSTAKA}

Ani Wahyuni, Rame Santoso, \& Sidik. (2019). Animasi Interaktif Pembelajaran Tata Cara Shalat Untuk Paud Enggunakan Adobe Flash Cs 6.0. Journal Speedentra Penelitian Engineering Dan Edukasi (Speed), 11(4), 56-64.

Apriansyah, M. R. (2020). Pengembangan Media Pembelajaran Video Berbasis Animasi Mata Kuliah Ilmu Bahan Bangunan Di Program Studi Pendidikan Teknik Bangunan Fakultas Teknik Universitas Negeri Jakarta. Jurnal Pensil, 9(1), 9-18. Https://Doi.Org/10.21009/Jpensil.V9i1.12905

Arsyad, A. (2002). Media Pembelajaran. Raja Grafindo Persada.

Daesang, K., Doong-Joong, K., \& Woo-Hyung, W. (2013). Cognitive Sinergy In Multimedia Learning. Canadian Center Of Science And Education, 6, 76-84.

Depdikbud. 2014. Peraturan Menteri Pendidikan Dan Kebudayaan Republik Indonesia Nomor 103 Tahun 2014 Tentang Pembelajaran Pada Pendidikan Dasar Dan Pendidikan Menengah. Jakarta: Depdikbud.

Danim, S. (2010). Media Komunikasi Pendidikan. Sinar Grafika.

Fuady, C.A. (2015). Pengembangan Media Animasi Flash Player Pada Materi Laju Reaksi Di Smk Negeri 1 Banda Aceh. Jurnal Pendidikan Dan Teknologi Informasi, 1(1), 34-47

Jannah, M., \& Julianto, J. (2018). Pengembangan Media Video Animasi Digestive System Untuk Meningkatkan Hasil Belajar Siswa Mata Pelajaran Ipa Kelas V. Jurnal Penelitian Pendidikan Guru Sekolah Dasar, 6(2), 254798.

Nugroho, S. 2008. "Pengembangan Media Pembelajaran Interaktif Mata Diklat Dasar Listrik Dan Elektronika Di Smk". Laporan Proyek Akhir, Jurusan Pendidikan Teknik Elektro Ft Uny

Sanjaya, W. (2010). Kurikulum Dan Pembelajaran: Teori Dan Praktik Pengembangan Kurikulum Tingkat Satuan Pendidikan (Ktsp). Kencana Prenada Media Group.

Saselah, Y.R., Amir, M., \& Qadar, R. (2017). Pengembangan Multimedia Interaktif Berbasis Adobe Flash Cs6 Professional Pada Pembelajaran Kesetimbangan Kimia. Jurnal Kimia \& Pendidikan Kimia, 2(2), 80-89

Serin, O. (2011). The Effect Of The Computer-Based Instructions On The Achievement And Problem Solving Sill Of The Science And Technology Students. The Turkish Online Journal Of Education Technology, 10, 183-201.

Sudjana, N. (2004). Penilaian Hasil Proses Belajar Mengajar. Remaja Rosdakarya.

Sugiyono. (2009). Metode Penelitian Pendidikan. Alfabeta

Sukarmin, S. (2019). Development Of Chemical On Household Interactive Multimedia And Kit For Hearing Impairment Students Of Junior High School For Disabilities. Jurnal Penelitian Pendidikan Sains (Jpps), 8(2), 1727-1734

Suyanto, M. (2003). Multimedia Alat Untuk Meningkatkan Keunggulan Bersaing. Andi. ..(2005). Multimedia Alat Untuk Meningkatkan Keunggulan Bersaing. Andi.

Wahyuni, S., \& Djukri, D. (2016). Pengembangan Media Pembelajaran Berbantuan Komputer Dan Keefektifannya Terhadap Kemandirian Belajar Dan Penguasaan Konsep Bryophyte. Jurnal Inovasi Teknologi Pendidikan, 3(1), 79-91 
507 Pengembangan Media Pembelajaran Adobe Flash CS6 pada Mata Pelajaran Teknologi Informasi dan Komunikasi untuk meningkatkan Hasil Belajar Siswa SMP - Zamza Satria Edwar, Romli Ardie, Lukman Nulhakim

DOI: https://doi.org/10.31004/edukatif.v4i1.1576

Wahyuningtyas, R., \& Sulasmono, B. S. (2020). Pentingnya Media Dalam Pembelajaran Guna Meningkatkan Hasil Belajar Di Sekolah Dasar. Edukatif : Jurnal Ilmu Pendidikan, 2(1), 23-27. Https://Doi.Org/10.31004/Edukatif.V2i1.77 